\title{
Enzyme production by Candida albicans and Candida dubliniensis in periodontal HIV-positive patients receiving and not receiving antiretroviral therapy
}

\author{
Verónica A. Dubois 1,5, María I. González 1,5 María E. Martínez' , Laura Fedelli1,5, Sabrina \\ Lamas' Luciana R. D`'Eramo 3,4,5, Aldo F. Squassi ${ }^{3,4,5}$, Gabriel A. Sánchez², ${ }^{2}$, Pablo \\ Salgado ${ }^{1,4,5}$, Laura A. Gliosca ${ }^{1,5}$, Susana L. Molgatini ${ }^{1,5}$. \\ ' Universidad de Buenos Aires. Facultad de Odontología. Hospital Odontológico Universitario. \\ Cátedra de Microbiología y Parasitología, Buenos Aires, Argentina. \\ ${ }^{2}$ Universidad de Buenos Aires. Facultad de Odontología. Hospital Odontológico Universitario \\ Cátedra de Biofísica y Bioestadística, Buenos Aires, Argentina. \\ ${ }^{3}$ Universidad de Buenos Aires, Facultad de Odontología, Clínica para La Atención de Pacientes de Alto Riesgo médico, \\ Buenos Aires, Argentina. \\ ${ }^{4}$ Universidad de Buenos Aires, Facultad de Odontología, Cátedra de Odontología Preventiva y Comunitaria, Buenos \\ Aires, Argentina. \\ ${ }^{5}$ Universidad de Buenos Aires, Instituto de Investigaciones en Salud Pública, Buenos Aires, Argentina.
}

\begin{abstract}
Candida dubliniensis $(\mathrm{Cd})$ and Candida albicans $(\mathrm{Ca})$ are the most frequently isolated yeasts in HIV+ patients. Some of the enzymes produced by these yeasts are considered virulence factors since they contribute to pathogenicity of Candida spp.

The aim of the present study was to compare production of enzymes such as phospholipase $(P h)$, proteinase $(P)$, and hemolysin (H) by $\mathrm{Cd}$ and $\mathrm{Ca}$ strains isolated from periodontal $H I V$-positive patients receiving and not receiving highly active antiretroviral therapy (HAART).

Subgingival biofilm samples were obtained using paper points, and a sample of oral mucosa was taken using a swab.

Phenotypic and molecular methods were used to isolate 39 strains of Candida, including 25 strains of $\mathrm{Cd}$ and 14 strains of $\mathrm{Ca}$, obtained from 33 periodontal pocket samples and 6 oral mucosa samples collected from $15 \mathrm{HIV}+$ patients (8 receiving and 7 not receiving HAART). Malt egg-yolk agar, albumin agar and blood agar were used to evaluate $\mathrm{pH}, \mathrm{P}$ and $\mathrm{H}$ production respectively. The strains were inoculated in duplicate
\end{abstract}

and incubated at $37^{\circ} \mathrm{C}$. Colony and halo diameters were measured.

A greater proportion of $C a$ was observed in patients not receiving HAART, and a higher proportion of Cd was observed in those under HAART, Chi $i^{2} p<0.001$. Phospholipase production was observed in $92.9 \%$ percent of isolated Ca strains but in none of the isolated $\mathrm{Cd}$ strains. Proteinase production was high in $\mathrm{Ca}$ and $\mathrm{Cd}$ strains isolated from patients not receiving HAART. Hemolysin production was observed in all the studied strains, though it was significantly higher $(p=0.04)$ in $C a$ and Cd strains isolated from patients not receiving HAART.

To sum up, the proportion of Candida dubliniensis strains was highest in the subgingival biofilm of patients receiving HAART, and Cd strains were found to express fewer virulence factors than Ca strains.

Received: March 2020: Accepted: June 2020.

Keywords: candida albicans- $H I V$ - periodontitis- antiretroviral therapy.

Producción enzimática de Candida albicans y Candida dubliniensis de pacientes con periodontitis $\mathrm{VIH}+$ con y sin tratamiento antirretroviral

\section{RESUMEN}

Las levaduras más aisladas en pacientes $\mathrm{VIH}+$ son Candida dubliniensis (Cd) y Candida albicans (Ca). Algunas de sus enzimas constituyen factores de virulencia ya que favorecen la diseminación tisular.

El objetivo fue comparar la producción de enzimas como fosfolipasa $(F)$, proteinasa $(P)$ y hemolisina $(H)$ en cepas de Cd y Ca aisladas de pacientes VIH+ tratados y no tratados con antirretrovirales (TARGA).

Se realizó la toma del biofilm de placa subgingival con conos de papel y la muestra de la mucosa bucal con hisopo.
Se aislaron y tipificaron por métodos fenotípicos y moleculares 39 cepas: 25 de Cd y 14 Ca, obtenidas 33 de bolsas periodontales y 6 de mucosa bucal de 15 pacientes VIH+ (8 con y 7 sin tratamiento). Se utilizó agar malta con yema de huevo, agar albúmina y agar sangre para demostrar la producción de $F, P y H$, respectivamente. Se inocularon por duplicado e incubaron a $37^{\circ} \mathrm{C}$. Se midieron los diámetros de las colonias y los de hidrólisis alrededor de las mismas.

Se observó mayor proporción de Ca en los pacientes sin tratamiento y mayor proporción de $\mathrm{Cd}$ en los con tratamiento; $C h i^{2} p<0.001$. 
El 92,9\% de las Ca estudiadas, fueron productoras de fosfolipasa. En tanto que ninguna Cd produjo la enzima.

En cuanto a la producción de proteinasa se observa una alta producción tanto en las cepas de Ca, como en las Cd aisladas en los pacientes no tratados.

Todas las cepas estudiadas produjeron hemolisina, observándose una diferencia estadísticamente significativa $(p=0,04)$ en ambas especies a favor de la alta producción de

\section{INTRODUCTION}

Colonization by Candida species begins within the first few days of life. Although the oral mucosa is a reservoir, Candida spp. are also present in the biofilm of periodontal pockets of patients with periodontitis, endodontic infection and periimplantitis ${ }^{1}$.

In 30 to $50 \%$ of subjects, Candida spp. colonize the oral cavity and the digestive tract, and are more frequent in lactating infants, elderly subjects who use a dental prosthesis, people who have received antibiotic treatment or chemotherapy, patients with poorly controlled diabetes, and hospitalized and immunosuppressed patients ${ }^{2}$.

Asymptomatic colonization of the oral mucosa is more prevalent among HIV+ subjects and considered an important predisposing factor for candidiasis.

The advent of highly active antiretroviral treatment (HAART) has markedly improved the immune system of HIV+ patients, substantially decreasing the incidence of opportunistic infections ${ }^{3}$.

The most frequently isolated yeasts form the oral cavity of HIV+ patients are Candida albicans and Candida dubliniensis. These species share a number of phenotypic features, such as the formation of green colonies in chromogenic media and the ability to produce chlamydospores and pseudofilaments ${ }^{4-7}$. The virulence factors of these yeasts include phenotypic change, dimorphism, adherence capacity and secretion of lytic enzymes such as phospholipase, proteinase and hemolysin, among others $^{8,9}$.

Production of these enzymes can therefore be an important determining factor of the potential of these microorganisms to produce invasive infection in certain groups of individuals, as is the case of immunocompromised patients ${ }^{10}$.

The aim of the present study was to describe and compare enzyme production by commensal strains of Candida albicans and Candida dubliniensis obtained from different oral ecological niches in periodontal $\mathrm{HIV}+$ patients, receiving and not la enzima en las cepas obtenidas de pacientes no tratados. Podemos concluir que en el biofilm subgingival, en los pacientes bajo TARGA, se aíslan mayor proporción de Candida dubliniensis las cuales expresan menos factores de virulencia.

Palabras clave: candida albicans- VIH- periodontitis- terapia antiretroviral.

receiving highly active antiretroviral therapy (HAART).

\section{MATERIALS AND METHODS}

The study population comprised adults living with HIV/AIDS residents in the Buenos Aires City, who attend dental care services. The sample included 15 HIV patients (8 receiving and 7 not receiving HAART) seen at the High-Risk Patients Oral Care Unit (CLAPAR I), School of Dentistry, University of Buenos Aires, who underwent oral examination after they had voluntarily signed an informed consent form. The study was approved by the Ethics Committee of the School of Dentistry, University of Buenos Aires (Resolution 21/11/2012-33).

Patients aged 18 to 60 years, diagnosed with HIV infection (confirmed by 2 positive ELISA tests and 1 Western Blot or similar), with a minimum 6 teeth and one site per quadrant with a probing depth equal to or higher than $5 \mathrm{~mm}$, attachment loss, and positive bleeding on probing, were included in the study. Only HAART patients who had remained on the same regimen the whole year prior to study enrolment were included.

Patients with systemic disease unrelated to HIV infection prior to or presenting during the study, receiving antibiotic/antifungal and/or oral-antiseptic treatment within 3 months prior to microbiological testing, showing mucosal candidiasis lesions, receiving oral care at other private or public oral health care services, and/or who smoked were excluded from the study.

Under adequate lighting conditions and using standardized instruments (a Marqis color-coded probe and a dental mirror), a calibrated researcher assessed the following clinical parameters of periodontal disease at 6 different sites per tooth $(3$ on the buccal aspect and 3 on the palatal or lingual aspect): presence of biofilm, probing depth (PD), clinical attachment level (CAL) and bleeding on probing (BP). 
The patients were then instructed to rinse their mouth with distilled water. The site showing the worst periodontal parameters in each quadrant was identified. Following removal of the supragingival plaque using a curette and tooth isolation with cotton rolls, subgingival biofilm samples were collected using 4 paper points placed one at a time into the depth of the pocket for 20 seconds. The obtained samples were placed in reduced transport fluid (RTF) medium. A sample of oral mucosa was obtained using a swab, which was placed in a tube containing RTF medium.

All the samples were submitted to the microbiology laboratory for processing.

\section{Microbiological Procedures}

The samples were homogenized by shaking in a vortex mixer; $50 \mu \mathrm{l}$ of each suspension were seeded in CHROMagar Candida ${ }^{\circledR}$ for presumptive identification of the species ${ }^{7}$.

C. albicans and C. dubliniensis were distinguished by using conventional phenotypic methods ${ }^{5,6}$ : cultures on milk-tween 80 agar for detection of germ-tubes, pseudofilaments, and chlamydospores ${ }^{11}$, cultures on Sabouraud Dextrose Agar (SDA) incubated at $45^{\circ} \mathrm{C}^{12}$, and cultures on Staib agar for production of chlamydospores ${ }^{13}$.

\section{Molecular identification}

Genomic DNA was extracted from pure and fresh 24-h cultures in SDA. Cell lysis was reached by heating at $100{ }^{\circ} \mathrm{C}$ and centrifuging at $16000 \mathrm{~g}$.

Two species-specific primers derived from the internally transcribed spacer (ITS) region (comprising the ITS1, 5.8s rRNA and ITS2 regions) as described by Asadzadeh et al. ${ }^{14}$ were used.

Amplification reactions were performed by real time PCR (qPCR) using $2 \mathrm{X}$ SYBR Green Supermix in a $10 \mu \mathrm{l}$ final volume, $10 \mu \mathrm{M}$ of each primer, and $2 \mu \mathrm{l}$ of genomic DNA, in a thermal cycler (CFX96 C1000 Touch, BioRad, Hercules, CA, USA). PCR cycling conditions were as follows: denaturation at $95{ }^{\circ} \mathrm{C}$ for 5 minutes, followed by 39 amplification cycles at $95{ }^{\circ} \mathrm{C}$ for 15 seconds, $60{ }^{\circ} \mathrm{C}$ for 30 seconds, $65{ }^{\circ} \mathrm{C}$ for 5 minutes, and $95{ }^{\circ} \mathrm{C}$ for 5 minutes.

The amplification process was evaluated using MCA (melting curve analysis) according to Asadzadeh et al. ${ }^{14}$.

\section{Detection of enzyme activity}

All the isolated strains were seeded in SDA and incubated at $37{ }^{\circ} \mathrm{C}$ for $18 \mathrm{~h}$. The cultures were used to prepare suspensions adjusted to $1 \mathrm{McFarland}$ standard $\left(1 \times 10^{6} \mathrm{CFU} / \mathrm{ml}\right)$.

Phospholipase, proteinase and hemolysin production was detected using malt agar supplemented with sterile egg yolk emulsion $(2 \%)^{8}$, bovine serum albumin agar $^{8}$, and SDA with sterile sheep blood $(7 \%)^{15}$, respectively.

Sterile paper discs were placed on the surface of each dish containing the corresponding medium, inoculated with $10 \mu \mathrm{l}$ of the suspension, and incubated under aerobic conditions at $37{ }^{\circ} \mathrm{C}$. The assays were performed in duplicate.

Phospholipase production was assessed at $72 \mathrm{~h}$ and was considered positive when a zone of precipitation was observed around the colony.

The precipitation zone $(\mathrm{Pz})$ value was calculated as the ratio of the diameter of the colony to the total diameter of the colony plus the precipitation zone ${ }^{16}$. Enzyme production was classified according to the $\mathrm{Pz}$ value as follows: Pz value $=0.35-0.5$ (high producers), Pz value $=0.51-0.74$ (moderate producers); Pz value $=0.75-$ 0.9 (low producers); and $\mathrm{Pz}$ value $=1$ (negative $)^{17}$.

Hemolytic halos were measured, and the enzymatic activity $\mathrm{Pz}$ value was calculated according to the ranges defined above.

Proteinase production was determined seven days post-incubation; the dishes were stained with a $0.6 \%$ amido black solution and destained with acetic acid $^{8}$. The presence of a hydrolysis zone around the colony showed positive proteinase activity.

Candida albicans ATCC 10231 was used as positive control for the production of all three enzymes, Candida glabrata ATCC 90030 was used as negative control for phospholipase, and Candida parapsilopsis ATCC 22019 was used as negative control for hemolysin and proteinase.

\section{Statistical Analysis}

Categorical variables were analyzed as frequencies and percentages using 95\% confidence intervals, and comparisons were established using Chi square test with Yates' continuity correction. In all cases, statistical tests for independent samples were used and level of statistical significance was less than 5\% to reject the null hypothesis.

All statistical analyses were performed using SPSS software version 26, MS Excel 2016, Epidat 4.0. 


\section{RESULTS}

As shown by the clinical records, 7 (46.7\%) of the 15 studied patients were women and 8 (53.3\%) were men, and all 15 patients contracted the virus by sexual transmission.

Mean age of the patients was 41 years $(\mathrm{SD} \pm 10$ years) and age range was 28 to 58 years. Analysis of the population according to age group showed that $20.0 \%$ were below the age of 30 years, $33.0 \%$ were between the age of 30 and 40 years, and $47.0 \%$ were over the age of 40 years.

Forty-seven percent of patients had been diagnosed with HIV within 10 years prior to the study, and $53.0 \%$ had been diagnosed more than 10 years before enrolment in the study. Eight patients (53.0\%) were receiving HAART and 7 (47.0\%) were not receiving HAART at the time of the study; $50 \%$ of patients receiving HAART had been under treatment for more than 10 years.

A total 75 samples, including 60 samples $(80.0 \%)$ of subgingival biofilm and 15 samples $(20.0 \%)$ of oral mucosa, were obtained from 15 patients. A total 39 strains of Candida genus were isolated: 14 (35.9\%) Candida albicans and 25 (64.1\%) Candida dubliniensis strains. Distribution according to species and localization is shown in Table 1.

\section{Table 1. Frequency and percentage distribution of Candida spp. according to localization.

\begin{tabular}{l|c|c|c|} 
& \multicolumn{3}{c}{ Candida spp. isolate } \\
\hline \multicolumn{1}{|c}{ Samples } & $\begin{array}{c}\text { Candida } \\
\text { albicans }\end{array}$ & $\begin{array}{c}\text { Candida } \\
\text { dubliniensis }\end{array}$ & $\begin{array}{c}\text { Total } \\
\text { strains }\end{array}$ \\
\hline $\begin{array}{l}\text { Periodontal } \\
\text { Sites }\end{array}$ & $12(85.7 \%)$ & $21(84.0 \%)$ & $33(84.6 \%)$ \\
Oral Mucosa & $2(14.3 \%)$ & $4(16.0 \%)$ & $6(15.4 \%)$ \\
\hline Total & $14(35.9 \%)$ & $25(64.1 \%)$ & $39(100.0 \%)$ \\
\hline
\end{tabular}

Both species were isolated from the same periodontal site in two patients, one receiving and one not receiving HAART.

No statistically significant differences in the distribution of Candida species or localization were observed; chi square test $\mathrm{p}=0.887$.

Analysis of the isolated species according to presence or absence of treatment showed 3 C. albicans (13\%) and 20 C. dubliniensis (87\%) strains in the 8 patients receiving HAART, and 11 C. albicans $(68.8 \%)$ and 5 C. dubliniensis $(31.2 \%)$ strains in the 7 patients not receiving HAART (Fig 1).

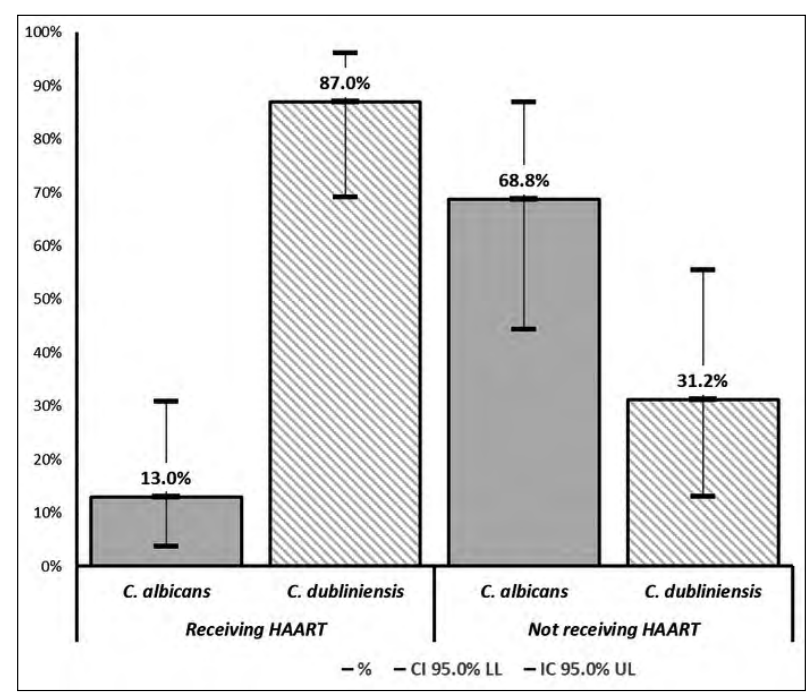

Fig. 1: Percentage distribution of Candida spp. according to presencelabsence of HAART.

Agreater proportion of Candida albicans was observed in patients not receiving HAART, and a higher proportion of Candida dubliniensis was observed in patients under HAART; Chi square test $\mathrm{p}<0.001$.

In view of the distribution of phospholipase and proteinase production, the statistical analysis was performed considering positive or negative production (presence /absence) and $\mathrm{Pz}$ values were not considered.

Phospholipase production was observed in 13 $(92.9 \%)$ of the 14 Candida albicans strains, 11 of which were isolated from patients not receiving HAART and 2 from patients under HAART (Table 2). However, no phospholipase production was observed in any of the Candida dubliniensis strains from either group.

\section{Table 2. Frequency and percentage distribution of phospholipase production by Candida albicans strains isolated from patients receiving and not receiving HAART.}

\begin{tabular}{|l|c|c|}
\hline \multirow{2}{*}{ Group } & \multicolumn{2}{|c|}{ Phospholipase production } \\
\hline Receiving HAART & Positive & Negative \\
\hline $\begin{array}{l}\text { Not receiving } \\
\text { HAART }\end{array}$ & $2(66,7 \%)$ & $1(33.3 \%)$ \\
\hline Total & $11(100,0 \%)$ & $0(0.0 \%)$ \\
\hline
\end{tabular}

Proteinase production was higher in both Candida albicans and Candida dubliniensis strains isolated from patients not receiving HAART; Chi square test, $\mathrm{p}<0,001$ (Fig. 2 and Table 3). 


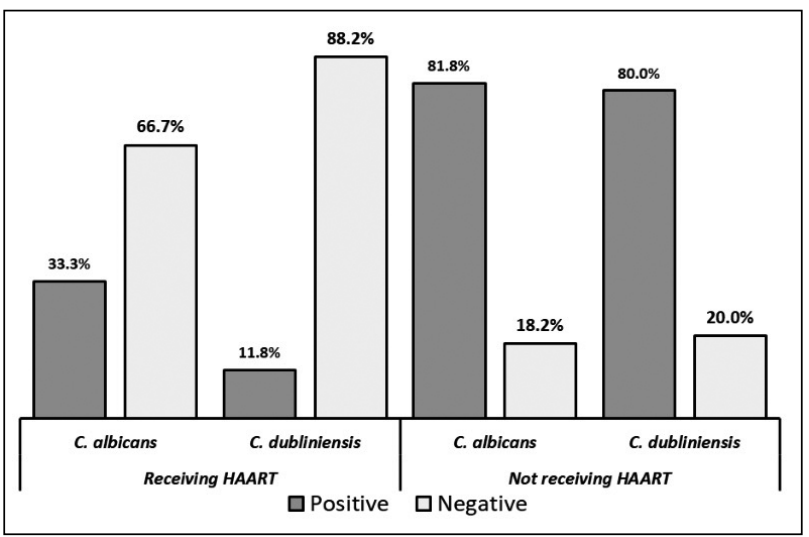

Fig. 2: Percentage distribution of proteinase production by Candida albicans and Candida dubliniensis strains isolated from patients receiving and not receiving HAART.

\begin{tabular}{l}
$\begin{array}{l}\text { Table 3. Frequency and percentage distribution } \\
\text { of proteinase production by Candida spp. } \\
\text { isolated from patients receiving and not } \\
\text { receiving HAART. }\end{array}$ \\
\begin{tabular}{l|c|c|}
\hline \multicolumn{1}{|c|}{ Group } & Proteinase production \\
\hline Receiving HAART & $3(15.0 \%)$ & $17(85.0 \%)$ \\
\hline $\begin{array}{l}\text { Not receiving } \\
\text { HAART }\end{array}$ & $13(81.2 \%)$ & $3(18.8 \%)$ \\
\hline Total & $16(44.4 \%)$ & $20(55.6 \%)$
\end{tabular} \\
\hline
\end{tabular}

As regards hemolysin production, all the studied strains were found to produce the enzyme, and production was significantly higher $(\mathrm{p}=0.04)$ both in $C a$ and in $C d$ strains isolated from patients not receiving HAART (Fig. 3 and Table 4).

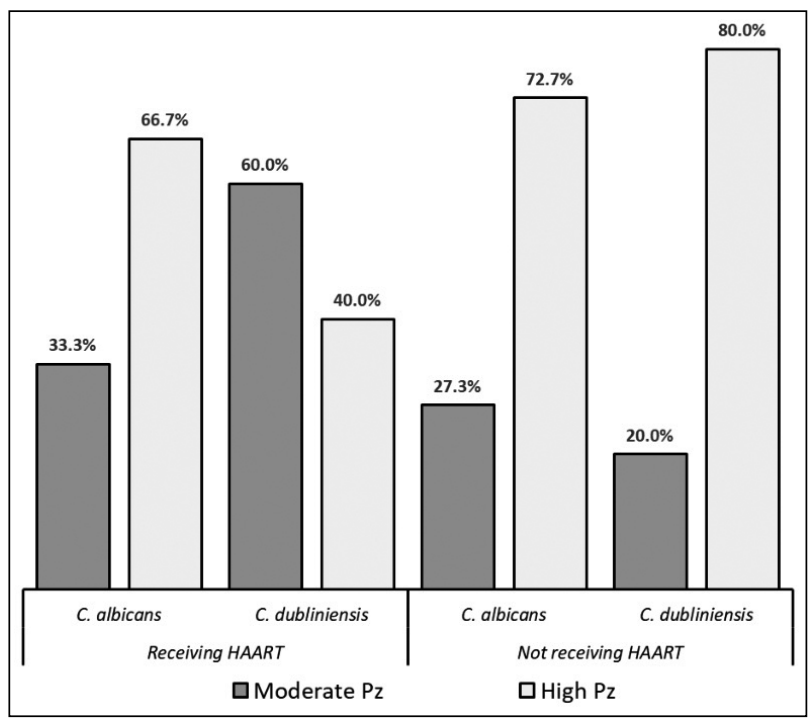

Fig. 3: Percentage distribution of hemolysin production by Candida albicans and Candida dubliniensis strains isolated from patients receiving and not receiving HAART.
Table 4. Frequency and percentage distribution of hemolysin production by Candida spp. isolated from patients receiving and not receiving HAART

\begin{tabular}{l|c|c|}
\multicolumn{1}{|c|}{ Group } & \multicolumn{2}{c|}{ Hemolysin production } \\
\hline Receiving HAART & $13(56.5 \%)$ & $10(43.5 \%)$ \\
\hline $\begin{array}{l}\text { Not receiving } \\
\text { HAART }\end{array}$ & $4(25.0 \%)$ & $12(75.0 \%)$ \\
\hline Total & $13(92.9 \%)$ & $1(7.1 \%)$ \\
\hline
\end{tabular}

\section{DISCUSSION}

The distribution of age, sex, and mode of acquisition of HIV infection was similar in both study groups of patients. Of note, all the studied yeast strains were isolated from oral mucosa and periodontal pockets of patients with no clinical manifestation of candidiasis.

In the present study, a larger number of strains of both Candida albicans and Candida dubliniensis was isolated from subgingival biofilm (Table 1).

Although the role of yeasts in the pathogenesis of periodontitis has not been fully elucidated to date, a number of authors have reported the presence of yeasts in periodontal pockets of subjects with chronic periodontitis, including both immunocompetent and immunocompromised patients ${ }^{18,19}$.

There are reports in the literature of Candida dubliniensis isolates from non-HIV patients ${ }^{20-22}$.

Ursua B. et al. found that $C$. albicans and $C$. dubliniensis were capable of colonizing periodontal pockets, regardless of pocket depth, in non-HIV patients with chronic periodontitis ${ }^{23}$.

According to Vieira Colombo AP et al., subgingival biofilm can be a source of development and dissemination of systemic infections ${ }^{24}$. Periodontal scaling could cause fungemia, which in turn could lead to serious complications, depending on the immunological status of the patient.

In the present study, a larger number of Candida dubliniensis strains were isolated from $\mathrm{HIV}+$ patients receiving HAART (Fig. 1), suggesting that compliance with treatment would result in homeostasis between the immunological status of the patient and the yeasts, decreasing the development of opportunistic infections, particularly candidiasis. Vilela MM et al. showed that Candida dubliniensis is less virulent than Candida albicans ${ }^{25}$.

Paula SB et al. recovered fewer Candida dubliniensis isolates from $\mathrm{HIV}+$ patients receiving $\mathrm{HAART}^{26}$. 
The detection of Candida species in periodontal pockets may be due to the ability of these yeasts to adapt to changes in the environment by altering $\mathrm{pH}$, oxygen concentration, and nutrient availability ${ }^{27}$. This enables them to coexist in the subgingival biofilm and coaggregate with periodontopathic bacteria, as shown in a paper recently published by our research team ${ }^{28}$.

According to Lourenço et al., the discrepancies among studies regarding the prevalence of Candida spp. could be due to the method used to collect the study samples, such as swabbing, collecting total saliva or oral rinses. ${ }^{29}$ In line with Samaranayake et al., the authors found that the oral rinse technique was the most sensitive for detecting Candida spp. ${ }^{30}$ We consider that collecting subgingival biofilm samples is an adequate method to recover Candida spp. Jewtuchowicz et al. isolated Candida spp. from subgingival samples obtained using a curette from immunocompromised patients ${ }^{22}$.

Several authors have reported coinfection by Candida dubliniensis and other Candida species, particularly Candida albicans. ${ }^{31}$ In the present study, we observed coinfection of a single site by both species in two cases: one patient under HAART and the other patient not receiving HAART.

All the strains were identified using phenotypic methods, and then confirmed using molecular biology techniques. Pineda G. et al. suggested that the combined use of at least three phenotypic differentiation techniques might be a valid alternative for laboratories that do not have access to molecular diagnostic methods ${ }^{6}$.

The transition of yeasts from commensal to opportunistic pathogens is the result of a number of mechanisms to overcome the host's defense barriers, including adhesion, biofilm formation and production of hydrolytic extracellular enzymes such as phospholipase and proteinase; all these properties are considered virulence determinants.

Aspartic proteases play an important role in the degradation of the mucosal (collagen, keratin,

\section{FUNDING}

The present study was supported by a Grant from University of Buenos Aires, UBACyT Program, code 20720160100002BA. and mucin) as well as the immune components (cytokines, antibodies, and complement), facilitating invasion of the host's tissues ${ }^{8}$.

Phospholipase can damage the host's cell membrane by degrading its constitutive lipids. Phospholipase production can therefore be an important factor in determining the ability of Candida spp. to invade tissues ${ }^{10}$.

Hemolysin production was observed in all the strains isolated in the present study. Manns et al. showed that iron is found intracellularly as ferritin or contained in the heme group, and that small amounts of extracellular iron are found bound to transport proteins such as transferrin and lactoferrin. Microorganisms also require iron to grow, and their ability to acquire iron is essential to their survival and to establishment of infection ${ }^{9}$. We understand that hemolysin production is a survival rather than a virulence factor.

The results of the present study showed that both species isolated from patients not receiving HAART produced proteinase (Fig. 2), whereas strains recovered from patients under HAART were low proteinase producers. As suggested by Thomas et al. ${ }^{32}$ and Ribeiro et al. ${ }^{33}$, this difference could be explained by the use of protease inhibitors in HAART. Nevertheless, other authors posit that the presence of protease inhibitors in HAART does not affect the production of this enzyme ${ }^{34-36}$.

In the present study, phospholipase production was observed in all the Candida albicans strains isolated from patients not receiving HAART, but in none of the Candida dubliniensis strains from either group of patients. Our findings are in line with studies testing different quantities of Candida dubliniensis strains $^{20,3,21}$.

\section{CONCLUSIONS}

A larger proportion of Candida dubliniensis strains were isolated from the subgingival biofilm of patients receiving HAART, and these strains had fewer virulence factors.

\section{CORRESPONDENCE}

Dr. Susana L. Molgatini

Cátedra de Microbiología

Facultad de Odontología, UBA

M.T. de Alvear 2142, Buenos aires

Argentina

smolgatini@yahoo.com.ar 


\section{REFERENCES}

1. Sardi JC, Duque C, Höfling JF, Gonçalves RB. Genetic and phenotypic evaluation of Candida albicans strains isolated from subgingival biofilm of diabetic patients with chronic periodontitis. Med Mycol 2012; 50:467-475.

2. Quindós G. Epidemiology of invasive mycoses: A landscape in continuous change. Rev Iberoam Micol 2018; 35:171-178.

3. Balero de Paula S, Tadachi Morey A, Pereira Santos J, dos Santos P, et al. Oral Candida colonization in HIV-infected patients in Londrina-PR, Brazil: antifungal susceptibility and virulence factors. J Infect Dev Ctries 2015; 9: 13501359.

4. Sullivan D, Coleman D. Candida dubliniensis: Characteristics and Identification. J Clin Microbiol 1998; 36:329-334.

5. López C, Giro L, Ramos L, Ramadán S, Bulacio L. Comparación de diferentes métodos para la identificación de especies del género Candida. Rev Argent Microbiol 2005; 37: 16-21.

6. Pineda G, Scollo K, Santiso G, Lehmann E, Arechavala A. Aislamiento de Candida dubliniensis en distintos materiales clínicos. Análisis de métodos fenotípicos de diferenciación con Candida albicans. Rev Arg de Microbiol 2008; 40: 211-217.

7. Odds F, Bernaerts R. CHROMagar Candida, a new differential isolation medium for presumptive identification of clinically important Candida species. J Clin Microbiol 1994; 1924-1929.

8. Ombrella A, Racca L, Ramos L. Actividades proteinasa y fosfolipasa de aislamientos de Candida albicans provenientes de secreciones vaginales con distintos valores de $\mathrm{pH}$. Rev Iberoam Micol 2008; 25: 12-16.

9. Manns J, Mosser D, Buckley H. Production of a Hemolytic factor by Candida albicans. Infect. Immun 1994; 5154 5156.

10. Echeverría A, Durante GA, Arechavala A, Negroni R. Estudio comparativo de dos medios de cultivo para la detección de la actividad de fosfolipasa en cepas de Candida albicans y Cryptococcus neoformans. Rev Iberoam Micol 2002; 19: 95-98.

11. Nota Técnica: medios de cultivo caseros para la identificación de hongos de interés médico. Rev Arg Micol 1994; 17: 26-33.

12. Gales AC, Pfaller MA, Houston AK, Joly S, Sullivan D J, Coleman DC, Soll DR. Identification of Candida dubliniensis Based on Temperature and Utilization of Xylose and a-Methyl-D-Glucoside as Determined with the API 20C AUX and Vitek YBC Systems. J Clin Microbiol 1999; 37: 3804-3808.

13. Staib P, Morschhäuser J. Chlamydospore formation in Candida albicans and Candida dubliniensis- an enigmatic developmental programme. Mycoses 2006; 50: 1-12.

14. Asadzadeh M, Ahmad S, Al-Sweih N, Ziauddin K. Rapid and Accurate Identification of Candida albicans and Candida dubliniensis by Real-Time PCR and Melting Curve Analysis. Med Princ Pract 2019; 27: 543-548.

15. Linares C, Loreto E, Silveira C, Pozzatti P, Scheid L, Santuario J, Alves S. Enzymatic and hemolytic activities of Candida dubliniensis strains. Rev Inst Med Trop Sao Paulo 2007; 49: 203-206.

16. Price M, Wilkinson I, Gentry L. Plate method for detention of phospholipase activity in Candida albicans. Sabouraudia 1982; 20:7-14.
17. Marcos-Arias C, Eraso E, Madariaga L, Aguirre JM, Quindós G. Phospholipase and Proteinase activities of Candida isolates from dentures wearers. Mycoses 2019; 54: 10-16.

18. Barros LM, Boriollo MF, Alves AC, Klein MI, Gonçalves RB, Höfling JF. Genetic diversity and exoenzyme activities of Candida albicans and Candida dubliniensis isolated from the oral cavity of Brazilian periodontal patients. Arch Oral Biol 2008; 53: 1172-1178.

19. De-La-Torre J, Quindós G, Marcos-Arias C, MarichalarMendia X, et al Oral Candida colonization in patients with chronic periodontitis. Is there any relationship? Rev Iberoam Micol 2018; 35:134-139.

20. Fotedar R, Al-Hedaithy SS Comparison of phospholipase and proteinase activity in Candida albicans and $\mathrm{C}$. dubliniensis. Mycoses 2005; 48: 62-67.

21. Hannula J, Saarela M, Dogan B, Paatsama J, et al. Comparison of virulence factors of oral Candida dubliniensis and Candida albicans isolates in healthy people and patients with chronic candidosis. Oral Microbiol Immunol 2000; 15 : 238-244.

22. Jewtuchowicz VM1, Mujica MT, Brusca MI, Sordelli N, Malzone MC, Pola SJ, Iovannitti CA, Rosa AC. Phenotypic and genotypic identification of Candida dubliniensis from subgingival sites in immunocompetent subjects in Argentina. Oral Microbiol Immunol 2008; 23: 505-509.

23. Urzúa B, Hermosilla G, Gamonal J, Morales-Bozo I, Canals M, Barahona S, Cóccola C, Cifuentes V. Yeast diversity in the oral microbiota of subjects with periodontitis: Candida albicans and Candida dubliniensis colonize the periodontal pockets. Med Mycol 2008; 46:783-793.

24. Vieira Colombo AP, Magalhães CB, Hartenbach FA, Martins do Souto R, Maciel da Silva-Boghossian C. Periodontaldisease-associated biofilm: A reservoir for pathogens of medical importance. Microb Pathog 2016; 94:27-34.

25. Vilela MM, Kamei K, Sano A, Tanaka R, et al. Pathogenicity and virulence of Candida dubliniensis: comparison with $\mathrm{C}$. albicans. Med Mycol 2002; 40:249-257.

26. Paula SB, Morey AT, Santos JP, Santos PM, et al. Oral Candida colonization in HIV-infected patients in LondrinaPR, Brazil: antifungal susceptibility and virulence factors. J Infect Dev Ctries 2015; 9:1350-1359.

27. Sardi JC, Duque C, Mariano FS, Peixoto IT, Höfling JF, Gonçalves RB. Candida spp. in periodontal disease: a brief review. J Oral Sci 2010; 52:177-185.

28. Gliosca LA, D’Eramo L, Bozza F, Soken L, Abusamra L, Salgado P, Squassi A, Molgatini S. Microbiological study of the subgingival biofilm in HIV+/HAART patients at a specialized dental service. Acta Odontol Latinoam 2019; 32: 147-155.

29. Lourenço AG, Ribeiro AERA, Nakao C, Motta ACF, Antonio LGL, Machado AA, Komesu MC. Oral Candida spp carriage and periodontal diseases in HIV-infected patients in Ribeirão Preto, Brazil. Rev Inst Med Trop Sao Paulo 2017; 59: e29. DOI: 10.1590/S1678-9946201759029.

30. Samaranayake LP, MacFarlane TW, Lamey PJ, Ferguson MM. A comparison of oral rinse and imprint sampling techniques for the detection of yeast, coliform and Staphylococcus aureus carriage in the oral cavity. J Oral Pathol 1986;15: 386-388.

31. Jabra-Rizk MA, Ferreira SMS, Sabet M, Falkler WA, Merz WG, Meiller TF. Recovery of Candida dubliniensis 
and Other Yeasts from Human Immunodeficiency VirusAssociated Periodontal Lesions. J Clin Microbiol 2001; 39 : 4520-4522.

32. Thomas S, Tsang CSP, Mathew A, Bhaskar S, Priya SP, Varughaes N. A Study on Exoenzyme Activities of Candida albicans Isolated from Oral Cavities of HIV-Infected Patients on HAART. J Hum Virol Retrovirol 2015; 2: 00037. DOI: 10.15406/jhvrv.2015.02.00037.

33. Ribeiro MA, Miranda AE, Gambale W, Paula CR. Prevalence and exoenzyme secretion by Candida albicans isolates from oral and vaginal mucosas of HIV-infected women. Mycopathologia 2004; 157: 255-261.

34. Back-Brito GN, El Achkar VNR, Garbim AL, Romeiro RL, Jorge AOC, Balducci I, Koga-Ito CY. HAART therapy does not reduce the proteinase and phospholipase secretion by oral Candida albicans isolated from HIV-positive patients. Rev Inst Adolfo Lutz 2011; 70:101-105.

35. Zanni PCMD, Bonfim-Mendonça PS, Negri M, Nakamura SS, Donatti L, Svidzinski TIE, Consolaro ME. Virulence factors and genetic variability of vaginal Candida albicans isolates from HIV-infected women in the post-highly active antiretroviral era. Rev Inst Med Trop Sao Paulo 2017; 59, e44. DOI: 10.1590/S1678-9946201759044.

36. de Paula Menezes R, de Melo Riceto ÉB, Borges AS, de Brito Röder DV, dos Santos Pedroso R. Evaluation of virulence factors of Candida albicans isolated from HIVpositive individuals using HAART. Arch Oral Biol 2016; 66: $61-65$. 